\title{
Predictors of progestin therapy response in endometrial hyperplasia: An immunohistochemical study
}

\author{
Muhammad Fawzy MD a, Alaa \\ Mosbah MD a, Abdelhadi M Shebl \\ $M D, P^{b}$, Khaled zalata MD ${ }^{b}$ \\ a- Department of Obstetrics \\ and Gynecology, Faculty of \\ Medicine, Mansoura University, \\ Egypt. \\ b- Department of Pathology, \\ Faculty of Medicine, Mansoura \\ University, Egypt.

\section{Running title:} \\ Is progestin therapy response \\ predictable in treatment of \\ endometrial hyperplasia?
}

Corresponding author:

Alaa Mosbah, MD

Department of Obstetrics

and Gynecology, Mansoura

University, Egypt.

Tel.: 00201227455978

E-mail: alaamosbah@hotmail.

com

Address: Obstetrics and

Gynecology Department,

Mansoura University, Mansoura,

Egypt.

Keywords:

Endometrial Hyperplasia:

Immunohistochemistry;

Progesterone Receptors;

Progestin, bcl2, p53

\section{$\underline{\text { Abstract }}$}

Background: Women with endometrial hyperplasia have an elevated risk of endometrial carcinoma. The first line of treatment of endometrial hyperplasia in premenopausal women is progestin treatment with variable response. Objectives: To evaluate the predictive value of immunohistochemical (IHC) biomarkers in progestin treatment for cases having endometrial hyperplasia.

Methods: A prospective trial was conducted among 50 premenopausal women with menometrorrhagia. Histopathological evaluation confirmed endometrial hyperplasia in pre-treatment endometrial biopsy [without atypia $(n=43)$ and atypia $(n=7)]$. All patients treated with oral progestin for 3-6 months. Endometrial immunohistochemical examination for progesterone receptors, $\mathrm{Bcl}$ 2 and p53 were analyzed in basal blocks.

Results: Study participants were classified into two groups, Group One showed endometrial response $(\mathrm{n}=38)$ and Group Two showed nonresponse or histological progression $(n=12)$. Immunohistochemical expression was expressed as a histopathological immunoreactive score (IRS). Immunoreactive score for progesterone receptors were significant higher in responders. Absence of progesterone receptors and presence of $\mathrm{p} 53$ predicted non-responder status.

Conclusions: Progesterone receptor expression may be a predictive biomarker of progestin response and p53 expression may be a predictive biomarker of progestin resistance.

\section{Introduction}

Endometrial hyperplasia (EH) is defined as abnormal proliferation of the uterine endometrial glands. Women with endometrial hyperplasia have an elevated risk of endometrial carcinoma (1). Hyperplasia of the endometrium is an estrogen dependent proliferation, there is agreement that progesterone or estrogen metabolism of the endometrium may be causal to the initiation, progression and malignant transformation of endometrial hyperplasia (2).

Endometrial hyperplasia is recently classified as hyperplasia without atypia (WAH) and atypical hyperplasia $(\mathrm{AH}) /$ endometrioid intraepithelial neoplasia. Hyperplasias without atypia exhibit no relevant genetic changes. They are benign changes and will regress again after the endocrine milieu (physiological gestagen levels) has normalized. In a few cases (1-3\%), progression to invasive disease may occur if the endocrine disorder (longterm estrogen dominance or relative or absolute gestagen deficiency) persists over the long term (3).

Atypical endometrial hyperplasias exhibit many of the mutations typical for invasive endometrioid endometrial cancer. In up to $60 \%$ of cases, patients are at extremely high risk of developing invasive cancer (4). 
Generally, WAH should be treated conservatively (normalization of the cycle through weight loss, metformin; cyclical gestagens; gestagen IUD). Preventive hysterectomy should only be considered in exceptional cases $(5,6)$. Treatment of AH/endometrioid intraepithelial neoplasia should generally consist of total (not supracervical) hysterectomy. Conservative treatment with high-dose gestagens and close histological monitoring should only be considered in exceptional cases (when the patient wants to have children, satisfactory compliance (7).

Progestin may induce EH regression by antagonizing estrogen-induced proliferation through decreased synthesis of estrogen receptors and conversion of estradiol to estron (8). These possible biological effects of progestin require the presence of progesterone receptors. There are two progesterone receptors (PR A and B). Both subtypes detected by the antibody recognizing both isoforms of the receptor. As previously reported, both PR was present in glands and stroma in the proliferative phase, and both subtypes were dramatically reduced in the glands during the secretory phase (9). Thus, expression of progesterone receptor in endometrium may identify progestin response in treatment of endometrial hyperplasia.

$\mathrm{Bcl}-2$ is a gene that suppresses programmed cell death (antiapoptosis) and is expressed in a variety of human neoplasms (10). Bcl-2 is expressed in the early stage of the neoplasm and is down-regulated with administration of progesterone (11). The tumor suppressor gene p53 is essential in the control of cell cycle progression and is the most frequently mutated gene in human tumors (12).

Up tell now, the first line of treatment of endometrial hyperplasia in premenopausal women is progestin treatment with variable response; so may be necessary to get valuable biomarkers that could predict oral progestin therapy response to guide treatment options. The purpose of this study was to investigate the efficacy of IHC biomarkers PR, Bcl-2 and p53 for predicting the efficacy of oral progestin treatment in endometrial hyperplasia.

\section{Patients and methods}

This prospective study was conducted from December 2012 through November 2014 at gynecology and pathology departments, Mansoura University. Selected group were premenopausal $(35-50$ y) women suffered from menometrorrhagia, thick endometrium $\geq 14 \mathrm{~mm}$ on ultrasound examination and endometrial hyperplasia with and without atypia in histopathological examination of basal (pre-treatment) endometrium . Body mass index was recorded for all cases. Exclusion criteria were coagulation disorders, hepatic patients or local organic lesions. A total of 52 women who met the inclusion criteria and gave informed written consent were recruited to the trial. This study was given approval by the ethics committee of Mansoura Faculty of Medicine.

All patients received cyclic oral medroxyprogesterone acetate (provera tablet, Pharmacia \&Upjohn, Pfizer) treatment. The dose was initiated at $20 \mathrm{mg}$ per day for 20 consecutive days monthly and decreased to 20 mg per day for consecutive 15 days based on clinical improvement after 3 months. Follow up endometrial examination was performed after 3-6 month therapy by Novake curette or hysterectomy.

The outcome was determined by comparing the diagnosis of the post-treatment biopsy to the pretreatment biopsy. After treatment, it was classified into two groups: Group One was defined as subjects showing endometrial regression (progestin effects) which includes: gland atrophy, glands separated by plump polygonal pseudo-decidualized stromal cells and epithelial metaplasia (13). Group Two was defined as subjects showing persisting hyperplasia and/or histological upgrading to atypical hyperplasia or endometrial cancer.

Paraffin wax embedded sections were stained with haematoxylin and eosin. The interpretation of endometrial histologies was made by two experienced gynecological pathologists according to WHO's criteria (3).

Immunohistochemical staining was performed on $4 \mu \mathrm{m}$ thick, formalin fixed, paraffin embedded tissue sections that were mounted on coated slide. DAKO kit (Dako REAL $^{\mathrm{TM}}$ EnVision ${ }^{\mathrm{TM}}$ Detection System, Peroxidase/ DAB, Rabbit/Mouse, Produktionsvej 42, DK-2600, Glostrup, Denmark) was used. The horseradish peroxidase and diaminobenzedene hydrochloride (DAB) are the enzyme and chromogen employed. The section was deparaffinized, followed by incubation in xylene and hydration in a series of decreasing concentration of ethanol. After that, heat-induced epitope retrieval was done using a pressure cooker and EDTA buffer (PH 9). The sections were washed in PBS buffer, and immersed in peroxidase-blocking solution of DAKO to inhibit endogenous peroxidase activity. The slide was incubated with primary antibodies, monoclonal mouse antihuman progesterone receptor (Clone PgR636, IR06861 (12 ml), ready to use (Link), Dako, North America, Inc.), monoclonal mouse antihuman Bcl-2 (Clone 124, IR61461 (12.0ml), ready to use, Neomarkers, Fremont, CA, USA), 
and monoclonal mouse antihuman p53 (Clone DO7, IR61661 (12.0ml), ready to use, Neomarkers, Fremont, CA, USA). The immune reactions were detected by incubating for $30 \mathrm{~min}$ at room temperature with labelled polymer (Labelled Polymer-HRP), from DAKO kit. The peroxidase activity was detected with diaminobenzidine as a chromogen, and the section was then counterstained with hematoxylin, dehydrate, coversliped, and mounted with DPX mounting media.

The slides were examined for Progesterone receptors A\&B by determining positively stained tumor cell nuclei. The progesterone receptor status was determined by a semiquantitative scoring scale with respect to staining intensity (grade: 0, absent; 1, weak; 2, moderate; and 3, strong) and percentage of positive cells $(0 \%$, indicating the absence of positive nuclei; 1 , presence of a few positive nuclei $<10 \%$; 2 , an estimated $10-50 \%$ positive nuclei; $3,51-80 \%$ positive nuclei; and $4,>80 \%$ positive nuclei). As recommended for breast cancer, and meningioma tissues, an immunoreactive score (IRS) was calculated for each tumor by multiplying the staining intensity by the indicator of positive tissue cells, producing an IRS range from 0 to 12 . Tissue with an IRS of 2 or more was considered as receptor positive (14).

Every slide was examined for Bcl-2 by identification of positively stained tissue cell cytoplasm. Immunohistochemical expressions of $\mathrm{Bcl}-2$ were scored as negative, weak (faint cytoplasmic staining), moderate diffuse cytoplasmic stain, and strong (diffuse intense cytoplasmic stain). The proportion of tissue cells, which had positive staining was considered. Mean percentage of positive epithelial cells were estimated in at least 5 areas at high magnification $(\times 400)$ and grouped as follows, $0=<5 \%$; $1=5-25 \% ; 2=25-50 \% ; 3=50-75 \%$; $4=$ $>75 \%$. The percentage and intensity were multiplied to produce a weighted score for every case (15). Each slide was examined for p53 by identification of positively stained tissue cell nuclei. The p53 immunostaining was determined as $0 \%$ for tissues without staining, 1 for $0-10 \%$ positive cells, 2 for $<50 \%$ positive cells and 3 for $>50 \%$ p53-positive cells (16).

Statistical analysis of data was performed by unpaired two-tailed t test and Fisher's test. A P value less than 0.05 was considered to be significant.

\section{Results}

Fifty two patients $(45 / 52$ WAH \& 7/52 AH) who met the above mentioned criteria were included in this study. Two patients of first group were lost to follow up and not included in the final analysis. Patient characteristics revealed no significant differences between both comparable groups (Table I).
The majority $(38 / 50,76 \%)$ of study participants responded to oral progestin therapy $(33 / 43,76.7 \%$ of patients with a baseline diagnosis of WAH, 5/7, 71.4\% of patients with a baseline diagnosis of $\mathrm{AH}$ ).

Nine patients $(9 / 33,27.3 \%)$ of WAH treated with progestin for 3 months while treatment continued for at least 6 months between pre-treatment and post-treatment biopsies in most of the study participants $(41 / 50,82 \%)$.

Persistence and progress of endometrial hyperplasia occur at follow-up in twelve women $(24 \%)$ of study groups, ten demonstrated persistent hyperplasia, one upgraded from without atypia to atypical hyperplasia and one diagnosed well differentiated Stage Ia carcinoma after atypical hyperplasia. Hysterectomies were performed in all twelve failed progestin therapy.

Group One responded to progestin therapy exhibited significant higher quantitative score for PR compared to non-responders in Group Two. Presence of bcl2, or p53, was not associated with progestin responsiveness (Table II). The low progesterone receptor expression predicted non-responder status. No associations were found between pre-treatment $\mathrm{Bcl}-2$ protein expression and hyperplasia persistence and progression. The expression of p53 was mild and focal in the endometrium of WAH. However, it was strong and diffuse in endometrium of $\mathrm{AH}$ and endometrial carcinoma.

\section{Discussion}

Failure of endometrial hyperplasia response to progestin therapy over variable time may be encountered in some patients. Progestin therapy was received for three to six months because many authors reported that failure of treatment after that time is an indication for hysterectomy $(17,18)$. Progestin therapy and Follow up as alternative to hysterectomy were selected in 7 patients with $\mathrm{AH}$ for preservation of fertility which consistent with guidelines of WHO 2014 which reported that progestin therapy may be used in atypical endometrial hyperplasia and grade 1 adenocarcinoma for conservation of the uterus and fertility (18). Highlighting the prognostic analysis of IHC biomarkers may be necessary to predict progestin response in both types of endometrial hyperplasia through analysis of baseline pre-treatment biomarker receptor status.

The association of three biomarker receptors expression to gestagen responsiveness was determined by a semi quantitative scoring scale with respect to staining intensity and percentage of positive tumor cells and immune-reactive score (IRS). We found over 3-6 months period that women treated with oral progestin had a 
$76 \%$ regression of $\mathrm{EH}$ (Fig. 1), in comparison to $24 \%$ of patients persisted or progressed after treatment. In a comparable study, oral progestin treatment was associated with $61 \%$ decreased risk of persistence/progression of $\mathrm{AH}$ as compared to women not treated (19).

Progesterone receptor immune reactivity (Fig. 2), was associated with high significant predictive value for responders. Progestin induces regression of endometrial hyperplasia by reversing the endometrial effect of estrogen, decrease synthesis of estrogen receptors, helping the enzyme conversion of estradiol to estrone (20). These possible biological effects of progestin require the presence of progesterone receptors. Thus, low progesterone receptor expression in some patients may predict progestin resistance in future management.

In the literature, there were 2 options of prediction of endometrial hyperplasia response to progestin therapy: molecular receptor-based assessment and cyto-architectural histological evaluation. This study supports molecular receptor-based assessment which consistent with Utsunomiya et al who found that women responded to medroxyprogesterone acetate had a greater expression of both PRA and PRB at index (21). On the other hand, Ferenczy and Gelfand documented progestin response was directly related to the absence of cytological atypia (22).

Also, another study failed to show a predictive value of sex steroid receptor status in oral 8-14 weeks progestin response (23).

These differences in result may be explained by dose, duration and forms of progestin therapy as mentioned by Reed 2009 who reported that 3-months trial of medroxyprogesterone acetate $10 \mathrm{mg}$ or norethindrone acetate $1 \mathrm{mg}$ /day followed by adequate sampling is not an unreasonable approach if a woman desires uterine conservation (19).

In this study, the p53 suppressor oncogene mutation IRS was found to be of a higher predictive value for failed gestagen therapy (Table 2). Sherman et al 1995 considered A p53 suppressor oncogen mutation a precursor of adenocarcinoma (24). Studies on molecular alterations involved in pathogenesis of endometrial cancer have revealed mutations in the p53 tumor suppressor gene and the accumulation of $\mathrm{p} 53$ protein has been detected in endometrial carcinomas $(25,26)$.

The antiapoptotic gene $\mathrm{Bcl}-2$ regulates programmed cell death and thus lengthens cell survival that aids in the spread of the tumor process. In this study, no association between baseline $\mathrm{Bcl}-2$ expression and $\mathrm{EH}$ persistence/ progression. Some studies documented Bcl-2 expression in the early stage of the neoplastic continuum (27). On the contrary, loss of expression is associated with a worse prognosis, greater depth of myometrial invasion, a more advanced disease stage, and a greater probability of lymph node metastases (28).

Results from our study may assist gynecologist in counseling women with hyperplasia specially if associated with atypia to make a decision of progestin therapy or hysterectomy based on immune histochemical biomarkers. Limitations considered in this study were the small sample size and follow up duration restricted to 6 months.

\section{Conclusions}

Progesterone receptor biomarker may predict progestin therapy response while p53 expression shows a valuable biomarker of progestin resistance in women with complex endometrial hyperplasia.

\section{Declaration of Interest}

The authors report no conflict of interest.

\section{$\underline{\text { References }}$}

1. Lacey JV Jr, Sherman ME, Rush BB, et al. Absolute risk of endometrial carcinoma during 20year follow-up among women with endometrial hyperplasia. J Clin Oncol. 2010; 28:788-792.

2. Ehrlich CE, Young PC, Cleary RE: Cytoplasmic progesterone and estradiol receptors in normal, hyperplastic, and carcinomatous endometrial: therapeutic implications. Am J Obstet Gynecol 1981; 141: 539-46.

3. Zaino R, Carinelli SG, Ellenson LH et al. Tumours of the uterine Corpus: epithelial Tumours and Precursors. In: Kurman RJ, Carcanglu ML, Herrington CS, Young RH, eds. WHO Classification of Tumours of female reproductive Organs. 4th ed. Lyon: WHO Press; 2014: 125-126.

4. Kandoth C, Schultz N, Cherniack AD et al. Cancer Genome Atlas Research Network. Integrated genomic characterization of endometrial carcinoma. Nature 2013; 497: 67-73

5. Kommission Uterus der Arbeitsgemeinschaft Gynäkologische Onkologie e.V. Interdisziplinäre S2k-Leitlinie für die Diagnostik und Therapie des Endometriumkarzinoms. In: Kommission Uterus der Arbeitsgemeinschaft Gynäkologische Onkologie e.V. in der Deutschen Gesellschaft für Gynäkologie und Geburtshilfe e.V. sowie in der Deutschen Krebsgesellschaft e.V., Hrsg. Leitlinien zum Zervixkarzinom, zum Endometriumkarzinom und $\mathrm{zu}$ den Trophoblasttumoren. München: W. Zuckschwerdt Verlag; 2008: 73-126 
6. Trimble CL, Method M, Leitao M etal. Management of endometrial precancers. Obstet Gynecol 2012; 120: $1160-1175$

7. Kommission Uterus der Arbeitsgemeinschaft Gynäkologische Onkologie e. V. Empfehlungen für die Diagnostik und Therapie des Endometriumkarzinoms. Aktualisierte Empfehlungen der Kommission Uterus auf Grundlage der S2k Leitlinie (Version 1.0, 01.06.2008) ohne Angabe der Evidenzlevel und Empfehlungsgrade (April 2013). Online: http:// www.ago-online.org last access: 01.01.2015.

8. Tseng L, Gurpide E. Induction of human endometrial estradiol dehydrogenase by progestins. Endocrinology 1975; 97: 825-833.

9. Wang H1, Critchley HO, Kelly RW, etal. Progesterone receptor subtype $\mathrm{B}$ is differentially regulated in human endometrial stroma. Mol Hum Reprod. 1998; 4 (4):407-12.

10. Vaskivuo TE, Stenback F, Tapanainen JS: Apoptosis and apoptosis-related factors $\mathrm{Bcl}-2$, Bax, tumor necrosis factor-alpha, and NF-kappa B in human endometrial hyperplasia and carcinoma. Cancer 2002; 95:1463-1471.

11. Vereide AB, Kaino T, Sager G, etal. Bcl-2, BAX, apoptosis in endometrial hyperplasia after high dose gestagen therapy: a comparison of responses in patients treated with intrauterine levonorgestrel and systemic medroxyprogesterone. Gynecol Oncol 2005; 97: $740-750$.

12. Levine AJ, Perry ME, Chang A, etal. The 1993 Walter Hubert Lecture: The role of the p53 minorsuppressor gene in tumorigenesis. BrJ Cancer 1994; 69:409-416

13. Varma R, Soneja H, Bhatia K, etal. The effectiveness of a levonorgestrel-releasing intrauterine system (LNG-IUS) in the treatment of endometrial hyperplasia-a long-term follow-up study. Eur J Obstet Gynecol Reprod Biol 2008; 139:169-75.

14. Roser F, Nakamura M, Bellinzona M, etal. The prognostic value of progesterone receptor status in meningiomas. J Clin Pathol 2004; 57:1033-1037.

15. Konno R, Yamakawa $H$, Utsunomiya $H$, etal. Expression of survivin and Bcl-2 in the normal human endometrium. Mol Hum Reprod. 2000; 6:529-34.

16. Porichi O1, Nikolaidou ME, Apostolaki A, etal. BCL-2, BAX and P53 expression profiles in endometrial carcinoma as studied by real-time PCR and immuno-histochemistry. Anticancer Res 2009; 29:3977-82.

17. Hammond R, Johnson J. Endometrial hyperplasia. Current Obstetrics and Gynaecology 2004; 40: 99 -103 .
18. American College of Obstetricians and Gynecologists. ACOG practice bulletin, clinical management guidelines for obstetriciangynecologists, number 65, management of endometrial cancer. Obstet Gynecol 2005; 106:413-425.

19. Reed SD, Voigt LF, Newton KM, etal. Progestin therapy of complex endometrial hyperplasia with and without atypia. Obstet Gynecol 2009; 113:655-662.

20. Graham JD, Clarke CL. Physiological action of progesterone in target tissues. Endocr Rev 1997; 18: 502-519.

21. Utsunomiya H, Suzuki T, Ito K, etal: The correlation between the response to progestogen treatment and the expression of progesterone receptor B and 17beta-hydroxysteroid dehydrogenase type 2 in human endometrial carcinoma. Clin Endocrinol (Oxf) 2003; 58:696-703.

22. Ferenczy A, Gelfand M. The biologic significance of cytologic atypia in progestogen-treated endometrial hyperplasia. Am J Obstet Gynecol 1998;160:126-31.

23. Masuzawa H, Badokhon NH, Nakayama K. Failure of down-regulation of estrogen receptors and progesterone receptors after medroxyprogesterone acetate administration for endometrial hyperplasia. Cancer 1994; 74:2321-28.

24. Sherman ME, Bur ME, Kurman RJ 1995: P53 in endometrial cancer and its putative precursors: evidence for diverse pathways of tumorigenesis Human pathol, 26:1268-74.

25. Kuwashima Y, Kurosumi M, Kobayashi Y, Tanuma J, Suemasu K, Higashi Y, et al1998: Random nuclear p53 overexpression pattern in tamoxifenmediated endometrial carcinoma. Int J Gynecol Pathol; 17:135-139.

26. 26- Ben-Hur H, Berman L, Sandler B, etal. Serological and immunohistochemical determinations of p53 protein in diagnosis of endometrial cancer: A comparative study. Eur J Gynaecol Oncol 1997;18: 400-406.

27. Kokawa K, Shikone T, Otani T, etal. Apoptosis and the expression of Bax and Bcl-2 in hyperplasia and adenocarcinoma of the uterine endometrium. Hum Reprod 200; 16: 2211-2218.

28. Erdem O, Erdem M, Dursum A, etal. Angiogenesis, p53 and bcl-2 expression as prognostic indicators in endometrial cancer: comparison with traditional clinicopathological variables. Int J Gynecol Pathol 2003; 22 (3): 254-60. 


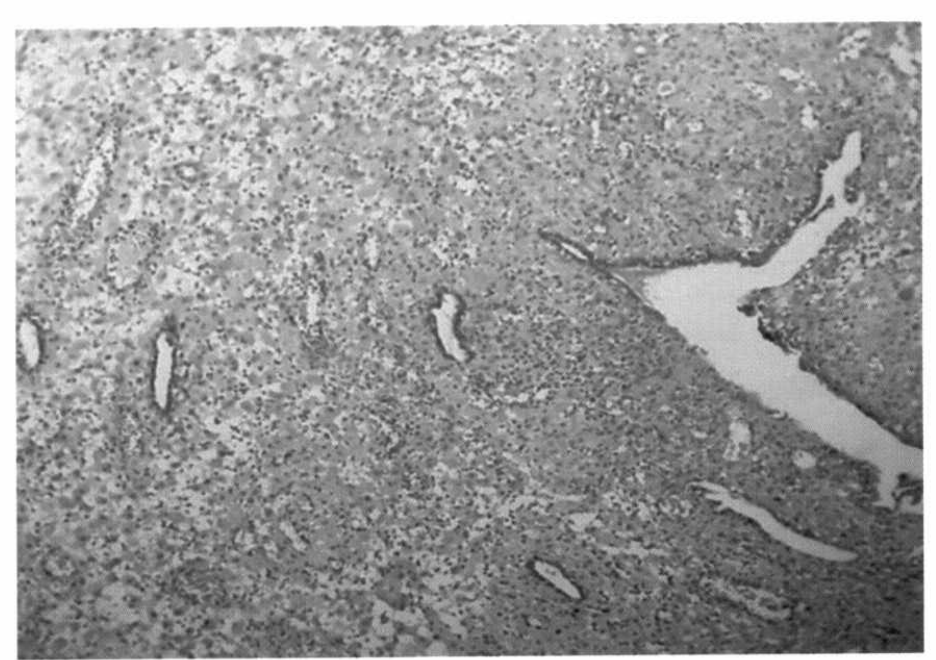

Figure (1)

Regressing endometrium after 6 months progestin therapy (H\&Ex100).

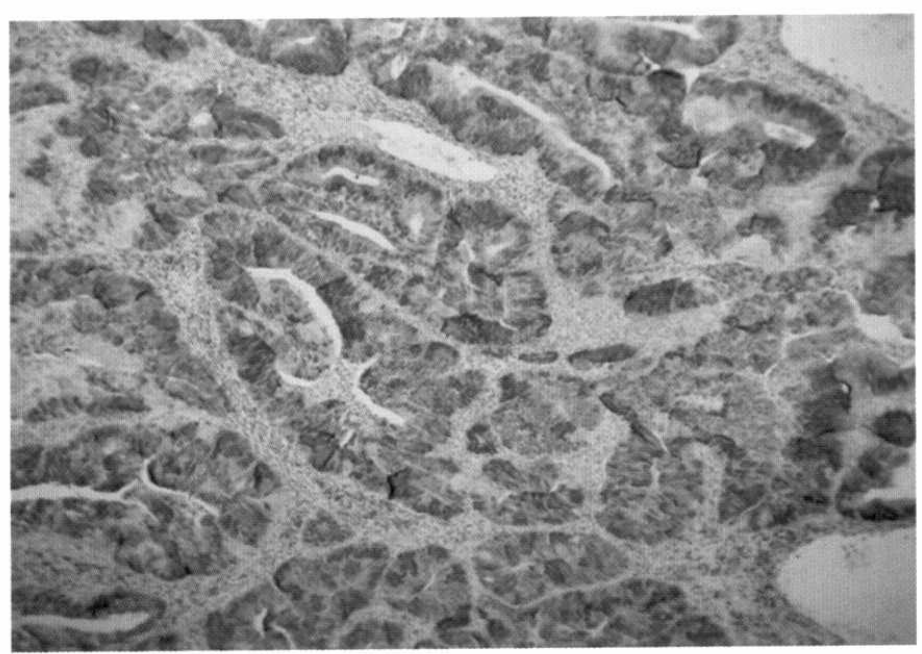

Figure (2)

Strong diffuse progesterone receptor immunoreactivity in atypical endometrial hyperplasia (x100).

Table I: Baseline characteristics $(\mathrm{n}=50)$

\begin{tabular}{|l|c|c|c|}
\hline & $\begin{array}{c}\text { Group One } \\
(\mathbf{n = 3 8})\end{array}$ & $\begin{array}{c}\text { Group Two } \\
(\mathbf{n = 1 2})\end{array}$ & p value \\
\hline -Age $(35-50 \mathrm{y}\}$ & $41.7 \pm 6.1$ & $43.2 \pm 5.3$ & $\mathrm{NS}$ \\
-BMI $(25-48 \mathrm{~kg} / \mathrm{m} 2)$ & $34.6 \pm 8.5$ & $32.7 \pm 7.6$ & $\mathrm{NS}$ \\
-Parity (0-6) & $2.5 \pm 1.1$ & $3.2 \pm 1.4$ & $\mathrm{NS}$ \\
*Hypertensive & $14(36.8 \%)$ & $4(33.3)$ & $\mathrm{NS}$ \\
*Diabetic & $5(13.1 \%)$ & $2(16.7)$ & $\mathrm{NS}$ \\
\hline
\end{tabular}

- Values in parentheses are ranges

$\mathrm{BMI}=$ body mass index.

* Values are numbers and percentages

Table II: Comparison of immuno-histochemical biomarkers expression in both groups

\begin{tabular}{|l|c|c|c|}
\hline & $\begin{array}{c}\text { Group One } \\
(\mathbf{n = 3 8})\end{array}$ & $\begin{array}{c}\text { Group Two } \\
(\mathbf{n = 1 2})\end{array}$ & p value \\
\hline Histology (50) & $33(76.7 \%)$ & $10(23.3 \%)$ & \\
- WAH (43) $\quad$ (7) & $5(71.4 \%)$ & $2(28.6 \%)$ & $<0.0001$ \\
PR & $6.78 \pm 2.81$ & $1.8 \pm 0.97$ & 0.2763 \\
Bc12 & $1.38 \pm 0.52$ & $1.2 \pm 0.41$ & $<0.0001$ \\
P53 & $1.1 \pm 0.45$ & $2.0 \pm 0.92$ & \\
\hline
\end{tabular}

-Values in parentheses are in percentages.

-The mean difference is significant at the 0.05 level

- Hyperplasia without atypia $=\mathrm{WAH}$

- Atypical hyperplasia $=\mathrm{AH}$

- Progesterone receptor $=\mathrm{PR}$ 